\title{
Pengaruh Kombinasi Metode Bobath Dan Neurosensomotor Untuk Peningkatan Postural Kontrol Duduk Pada Delay Development
}

\begin{abstract}
Titin Kartiyani ${ }^{1)}$ Muhammad dimas zam zami ${ }^{2)}$
1) Stikes Al Irsyad Al Islamiyyah Cilacap tien.fisio@gmail.com

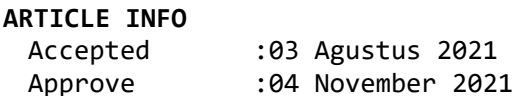

ABSTRACT

In this case of growth and development, the prevalence of significant growth retardation in the pediatric population is not yet clear.A child's growth and development disorder, commonly known as Delay Development, is a disorder that attacks the child's growth and development process, in this case, a child's growth and development disorders such as cognitive, gross motoric, fine and emotional. The purpose of this study was to determine whether there is an effect of a combination of bobath exercise and neurosensomotor on sitting postural control on developmental delay. This research is a pre-experimental design, with a one group pretest-post test design. After the difference test between the pre-test data and post-test data using the Paired T-test, the results were $p=0.0001(p$ $<0.05)$. This means that the hypothesis can be accepted and thus it can be concluded that there is an effect of a combination of bobath exercise and neurosensomotor on the ability to sit posture.
\end{abstract}

Keywords: Kombinasi, Delay Development, Postural, bobath exercise, neurosensomotor.

\begin{abstract}
ABSTRAK
Dalam kasus tumbuh kembang ini prevelensi keterlambatan tumbuh kembang yang signifikan di dalam populasi anak belum begitu jelas. Gangguan tumbuh kembang anak yang biasa disebut dengan Delay Development merupakan suatu gangguan yang menyerang pada proses tumbuh kembang sang anak, dalam hal ini gangguan tumbuh kembang mengenai beberapa ranah seperti kognitif, motorik kasar, halus maupun emosional anak. Tujuan dari penelitian ini adalah mengetahui apakah ada pengaruh kombinasi bobath exercise dan neurosensomotorik terhadap komtrol postural duduk pada delay development. Penelitian ini bersifat Pre-Experimental Design, dengan rancangan one group pretest-post test design. Setelah dilakukan uji beda antara data pre- test dengan data post-test menggunakan Uji T Berpasangan didapatkan hasil $p=0,0001(\mathrm{p}<0.05)$. Hal ini berarti hipotesis dapat diterima dan dengan demikian dapat disimpulkan bahwa terdapat pengaruh kombinasi bobath exercise dan neurosensomotorik terhadap kemampuan postural duduk..
\end{abstract}

Kata kunci:Kombinasi,Delay Development,Postural,bobath exercise, neurosensomotorik 


\section{PENDAHULUAN}

Dalam kasus tumbuh kembang ini prevelensi keterlambatan tumbuh kembang yang signifikan di dalam populasi anak belum begitu jelas. Perhitungan statistik, 2-3\% bayi berada diluar rentang tonggak pencapaian motorik normal. Dari angka tersebut, sebagian kecil (15-20\%) diketahui mempunyai diagnosis gangguan tumbuh kembang yang signifikan berupa cerebral palsy atau defek pada saat lahir. Gangguan tumbuh kembang anak yang biasa disebut dengan Delay Development merupakan suatu gangguan yang menyerang pada proses tumbuh kembang anak, hal ini gangguan tumbuh kembang mengenai beberapa ranah kognitif, motorik kasar, halus maupun emosional anak. Delay development merupakan suatu gejala penyakit tumbuh kembang pada anak yang ditandai dengan adanya delay atau keterlambatan saat tumbuh kembang berlangsung (Van 2017 Cit Karanganyar 2018). Penanganan keterlambatan tumbuh kembang atau delay development ini harus ditangani lebih sering, agar mempermudah atau memperingan suatu aktivitas yang dilakukan oleh penderita.Tindakan yang diberikan kepada penderita berupa terapi fisik.(Nur 2013). Postural control merupakan suatu istilah yang digunakan untuk menggambarkan cara sistem saraf pusat mengatur informasi sensorik dari sistem lain untuk menghasilkan output motor yang memadai untuk mempertahankan postur tubuh, Sistem visual, vestibular, dan somatosensori merupakan sistem sensorik utama yang terlibat dalam postural control (Ivanenko and Gurfinkel 2018).

Pada delay development ini dapat diatasi oleh berbagai modalitas fisioterapi, yaitu modalitas Bobath Exercise dan neurosensomotor.Bobath Exercise merupakan metode terapi latihan untuk mengatasi gejala keterlambatan atau kelumpuhan pada otak (Raine, Meadows, and LynchEllerington 2009). Sedangkan Neurosensomotorik adalah suatu teknik yang menggunakan kemampuan otak 
dilihat dari neurofisiologis dan neuropsikologis dengan memanfaatkan plastisitas dan sensitivitas otak yang bertujuan untuk membangun brain body conection. Berdasarkan latar belakang METODE

Penelitian ini bersifat preexperimental design, dengan rancangan one group pre test-post test design yang artinya bahwa terdapat suatu kelompok diberi treatment perlakuan dan selanjutnya diobservasi hasilnya, akan tetapi sebelum diberikan perlakuan terdapat pretest untuk mengetahui kondisi awal. Dengan demikian, hasil perlakuan dapat lebih akurat pengaruhnya karena dapat membandingkan dengan keadaan sebelum diberi perlakuan. Metode penelitian ini juga nantinya akan berguna untuk menganalisa perubahan distribusi kemampuan postural duduk pada anak Delay Development sebelum dan setelah mendapatkan intervensi berupa kombinasi Bobath Exercise dan neurosensomotorik. Penelitian ini akan dilakukan di Klinik Rinjani Medika selama 3 bulan .

\section{Subyek penelitian}

tersebut peneliti ingin mengetahui Pengaruh kombinasi bobath exercise dan neurosensomotor untuk control postural duduk pada kasus delay development.

Subyek penelitian adalah anak delay development. Teknik pengambilan sampel pada penelitian ini dengan kriteria inklusi : anak delay development dan sedang menjalani fisioterapi dan mengalami gangguan postur duduk.

Pengambilan sampel dilakukan dengan langkah sebagai berikut:

1) Menentukan sampel

Sampel dalam penelitian ini adalah delay development

2) Pemilihan sampel data

Dari jumlah populasi pasien tersebut, diambil sejumlah 20 sampel .

Proses pemilihan sampel dilakukan secara purposive sampling :

a. Variabel dan definisi Operasional Variabel dalam penelitian ini adalah Bobath Exercise dan neurosensomotorik

b. Instrumen Penelitian 
Instrumen yang digunakan dalam penelitian ini adalah Skor LSS

\section{HASIL}

Penelitian ini dilakukan di Klinik Rinjani Medika Cilacap. Banyaknya sampel adalah 20. Pengambilan data berlangsung selama 2 bulan dengan data pre test dan post tes sebagai berikut :

\section{Tabel 1.1 Karakteristik subyek}

\begin{tabular}{lll}
\hline $\begin{array}{l}\text { Karakteristik } \\
\text { subyek }\end{array}$ & Rentangan & jml \\
\hline Umur & $2-5$ & 20 \\
\hline Jenis kelamin & perempuan & 11 \\
\hline & Laki - laki & 9 \\
\hline
\end{tabular}

Tabel 1.2 Hasil pre test- post test

\begin{tabular}{llll}
\hline Test & Mean & Std. deviasi & p-value \\
\hline Pre test & 3.85 & 1.843 & 0,0001 \\
\hline Post test & 5.30 & 2.154 & \\
\hline
\end{tabular}

Berdasarkan pada tabel 1.1 diketahui terdapat nilai postural duduk sebelumnya rata - rata postural 3,85 dengan standar deviasi 1,843. Setelah diberikan intervensi perubahan terdapat kenaikan rata - rata postural 5,30 dengan standar deviasi 2,154

\section{PEMBAHASAN}

Dalam penelitian ini Sampel penelitian adalah anak delay development yang sedang menjalani pelayanan fisioterapi di di Klinik Rinjani Medika Cilacap..
Anak yang menjadi sampel berjumlah 20 orang terpilih dari kriteria inklusi dan ekslusi yang telah ditentukan sebelumnya.

Pada Pemeriksaan postural duduk pada penelitian ini menggunakan parameter Level of Sitting Scale (LSS) yang terdiri dari 8 level kemampuan postural duduk. Berdasarkan kriteria inklusi, pasien dengan nilai LSS I - VII yang akan menjadi sampel penelitian sedangkan yang mempunyai nilai LSS VIII tidak dimasukkan menjadi sampel 
penelitian karena sesuai dengan kriteria Level of Sitting Scale (LSS), nilai VIII adalah nilai maksimal yang dapat dicapai pada pemeriksaan ini.

Setelah data pre-test didapatkan maka dilanjutkan dengan melakukan intervensi kepada setiap sampel selama 24 kali pertemuan. Kemudian setelah menjalani 24 kali pertemuan, maka setiap sampel akan diukur kembali menggunakan parameter yang sama untuk mendapatkan data post-test.

Jika dibandingkan hasil pemeriksaan setelah mendapat perlakuan selama 24 kali, pada pemeriksaan post-test telah didapatkan sampel yang memiliki nilai LSS hingga tingkat VIII sebanyak 4 orang. Setelah dilakukan uji beda antara data pre- test dengan data post-test menggunakan Uji $\mathrm{T}$ Berpasangan didapatkan hasil $\mathrm{p}=$ $0,0001(\mathrm{p}<0.05)$. Hal ini berarti hipotesis dapat diterima dan dengan demikian dapat disimpulkan bahwa terdapat pengaruh kombinasi bobath exercise dan neurosensomotorik terhadap kemampuan postural duduk.

\section{SIMPULAN}

Simpulan dari penelitian ini adalah terdapat perbedaan pengaruh kombinasi bobath exercise dan neurosensomotor Untuk postural duduk pada anak delay development.

\section{DAFTAR PUSTAKA}

Huber. (2007). The Baby Book ( segala hal yang anda ketahui tenteng bayi anda sejak lahir hingga usia dua tahun). Jakarta: Serambi Ilmu Semesta.

Ivanenko, Yury, and Victor S. Gurfinkel. 2018. "Human Postural Control." Frontiers in Neuroscience. https://doi.org/10.3389/fnins.2018 .00171 .

Karanganyar, D I Pntc. 2018. "Penatalaksanaan Fisioterapi Pada Kondisi Global Delay Development Dengan Riwayat Congenital Rubella Syndrome.”

Michielsen, Marc, Julie VaughanGraham, Ann Holland, Alba Magri, and Mitsuo Suzuki. 2019. "The Bobath Concept - a Model to Illustrate Clinical Practice." Disability and Rehabilitation. https://doi.org/10.1080/09638288. 2017.1417496.

Nur,Anasta.2013.“PENATALAKSAN AAN FISIOTERAPI PADA KONDISI DELAY DEVELOPMENT DI YAYASAN PENDIDIKAN ANAK CACAT SURAKARTA," 15.

Probosuseno. (2007). Agar Olahraga Bermanfaat Untuk Kesehatan. 
http://www.republika.co.id.

Diakses pada 15 Februari 2018

Raine, Sue, Linzi Meadows, and Mary Lynch-Ellerington. 2009. Bobath Concept. Edited by Sue Raine, Linzi Meadows, and Mary LynchEllerington. Bobath Concept: Theory and Clinical Practice in Neurological Rehabilitation. Oxford, UK: Wiley-Blackwell. https://doi.org/10.1002/97814443 14601.

Swandari, A. (2015). Pengaruh Senam Bayi Terhadap Kecepatan Kemampuan Motorik Kasar Pada Bayi Usia 5 Bulan. Jurnal Insan Cendekia. Volume 1 No 2 Mei 2015 